\title{
Goods, Principles, and Values in the Brighouse, Ladd, Loeb and Swift Framework for Educational Policy-Making
}

\author{
Lars Lindblom ${ }^{1}$ (i) \\ Published online: 12 July 2018 \\ (c) The Author(s) 2018
}

\begin{abstract}
This article presents the promising framework for educational decision makers developed by Brighouse, Ladd, Loeb, and Swift (BLLS). The framework consists of an account of the educational goods, distributional principles and independent values at stake in education, and a method for making policy decisions on the basis of these and solid social science. I present three criticisms of this approach. The first says that the derivation of educational goods proceeds on the basis of a too narrow conception of values. I suggest that this foundation should consist of an overlapping consensus, rather than flourishing. The second criticism has to do with the way that the distributive principles are characterized. I argue that BLLS's characterization of distributive principles should be complemented with accounts of what domains of social life these principles regulate and a specification of whether the distributive principles should be understood as applying over time or at specific instances. The final criticism is that BLLS's conception of independent values focuses solely on values that constrain the pursuit of educational goods. I claim that this part of the framework should be revised to include aspects of values that also support this pursuit. I conclude arguing that the BLLS frameworks should be further developed rather than rejected.
\end{abstract}

Keywords Educational goods $\cdot$ Childhood goods · Distributive justice $\cdot$ Distribuendum · Educational policy making $\cdot$ Trade-offs in education

\section{Introduction}

If one wanted a new framework for thinking about values and decision-making in educational policy, one would probably want the group developing it to consist of philosophers and social scientists with backgrounds in educational policy and social science, as well as the philosophy of education and childhood. In Educational Goods: Values, Evidence, and Decision-Making (Brighouse et al. 2018; cf. Brighouse et al. 2016), this is exactly what one gets. As one would suspect, the framework developed by Brighouse, Ladd, Loeb, and Swift (BLLS) is both useful for policy purposes and based on a thorough analysis of the

Lars Lindblom

lars.lindblom@umu.se

1 Department of Historical, Religious and Philosophical Studies, Umeå University, Humanisthuset, 10044 Umeå, Sweden 
philosophical issues involved in education. The BLLS framework consists of an account of the normative issues at stake in education, and a method of developing policy based on those values and solid social science.

The purpose of this paper, however, is to argue that there are some problems with this framework that call for revisions of it. These issues revolve around the framework's conception of values. More specifically, I shall claim, first, that its account of educational goods is based on a too narrow interpretation of values, and argue for a more inclusive account of educational goods and a different individuation of them. Second, the distributive principles of the BLLS framework should be further specified and include the components of domains and timeframes of distribution. The domain of a distributive principle specifies what part of social life-from the global level to individual choices—it regulates, whereas the timeframe concerns whether distributive principles should be understood as applying over time or at specific instances. Third, the framework's account of independent values - values that are not educational goods or distributive principles, but still are relevant for education-is focused solely on such values that constrain the pursuit of educational goods and should be revised to include aspects of these independent values that support that pursuit. Finally, however, I shall claim that even if these criticisms were to be found correct, this should not be taken as reasons to reject the BLLS framework, but as a call for further development and debate of it.

The paper is structured as follows. In the second section, I start outlining the BLLS framework and then focus on the derivation of educational goods in the framework. I identify a problem with taking flourishing as a foundational value for education and suggest a way of handling this problem. I will also argue that childhood goods should be thought of as a part of educational goods. The third section argues that the conception of distributive principle in the BLLS framework needs to be complemented with further aspects of such principles. The fourth section is devoted to discussing the BLLS account of values independent of education and aims to show that this account is excessively focused on values that restrict the pursuit of educational goods. In the conclusion, the argument is brought together, and I argue that the BLLS framework gives us a fruitful approach to educational policy which should be further developed.

\section{The BLLS Framework and Educational Values}

The BLLS framework is developed to offer a way of thinking about values and polcy-making for decision makers and researchers in education. The resulting framework does two things. It gives an account of values and it presents a method for policy making. The latter consists of four steps.

1. Identify the main values in play.

2. Identify the key decisions relevant to those values.

3. Assess the options in the light of the values and evidence.

4. Establish what is the best policy overall in the circumstances (Brighouse et al. 2018, p. 76).

This process is often iterative. For instance, the identification of key decisions may show that one needs to go back from step 2 to step 1 and continue the process of identifying the relevant values. The topic of the present article, however, is on the other, and 
prior part, of the BLLS framework, namely the conception of values that it provides. BLLS identify three kinds of values: educational goods, distributive principles and independent values. The category of educational goods comprises of the capacities for the following: economic productivity, personal autonomy, democratic competence, healthy personal relationships, regarding others as equals, and personal fulfillment (Brighouse et al. 2018, p. 23-27). What the entries on this list have in common is that they all fall under the following definition of educational goods: "the knowledge, skills, dispositions, and attitudes that children develop both for their own benefit and for the benefit of others." (Brighouse et al. 2018, p. 2)

The value of flourishing takes center stage in BLLS's account of educational goods, but the way that it plays a role is complex. The fundamental dimension of value is not flourishing in itself, but opportunities for flourishing. To see why, according to BLLS, this is the right moral foundation for educational goods, we need to look closer at the concepts of flourishing and opportunity. Flourishing lives are characterized as "lives [that] go well" (Brighouse et al. 2018, p. 21) This characterization is compatible with a number of specifications, and BLLS refrains from taking a stand for any one of those, even if they in an article presenting the framework (Brighouse et al. 2016, p. 23, footnote 3) note that their own view is akin to what is called the capability approach, and Brighouse (2006) in another book on education defends a particular account of flourishing. BLLS continue:

We focus on opportunities for flourishing, rather than flourishing itself, because the most educational goods can do is equip people with what they need for their lives to go well, including the capacity to make good choices. Whether people do in fact choose well is a further question. (2006, p. 6)

In other words, the fundamental value underlying educational goods is the value of giving people opportunities for flourishing. This seems almost uncontroversial, but both parts of this notion are in fact very controversial in political philosophy. The flourishing view is standardly taken to imply that there are ways for people to live that amount to living well and other ways that do not qualify as living well. Flourishing is, therefore, controversial as a political goal since it may constrain the possibilities for people to choose their own path in life. If the state, or in this case the educational system as a subpart of the basic structure of society, is to promote flourishing, or opportunity for flourishing, it must decide what a good life is, or at least on a range of ways of living that qualify as good. Moreover, this means that a choice must be made regarding which way of living that are not good enough to be promoted. To intend, in this way, to promote specific ways of living is clearly in tension with the liberal ideal of state neutrality. (Cf. Brighouse 2000, pp. 7-8) In other work, Brighouse and Swift (2018) have discussed the controversial nature of flourishing and downplayed the perfectionist aspects of this value. They have done so for two reasons. First, they have wanted to avoid that anti-perfectionist would have reason to reject their account of flourishing out of hand. Second, they acknowledge the force of neutralists concerns. Now, the educational goods that BLLS list are clearly less controversial than the foundational value they are derived from. This indicates that the grounding of the framework is more fragile than would be necessary if another approach to the justification of educational goods could be found. Is there some other way to justify the list of goods?

A salient approach is to turn to the debate of what should be the metric of distributive justice, and what in an important sense was the starting point for that debate: the resourcism of Rawls (1971) and Dworkin (2000). Resourcists argue that the so-called distribuendum of justice should be resources because resources satisfy neutrality while also taking account of people's responsibility for their lives going well. Many things can serve as 
resources, but the gist of this theory is probably most easily explained by the resource of money. If people are given money, they are not tied to any specific lifestyle since they can use it for any purpose they see fit. In this sense, the resource of money satisfies neutrality. The claim here is not that money should be the distribuendum for education. Rather, the aim is to suggest that the educational goods that BLLS identify could equally well be thought of as being based on a resourcist account of what should be distributed as on the basis of flourishing, and that the former also is compatible with neutrality.

Resourcism is not the only approach that one could take to educational goods. Another position is that the grounding of educational goods in some other value is unnecessary since values are plural at the fundamental level. Pluralist, such as Berlin (2013), argue that there are many values and that the goal of normative theory is not to reduce them to one master value, but to handle the conflicts and trade-offs between values. On such a view, one could just let the educational values stand as they are. Of course, both resourcism and pluralism are also controversial; the proponents of flourishing obviously disagree that the metric of justice should be resources or thought of as standalone values. However, there is an aspect of theories developed to justify resourcism that may be of help to resolve the issue. This is Rawls's concept of an overlapping consensus (Rawls 2001). The Rawlsian idea is that a justification for a theory of justice must be such that it is accessible to all reasonable moral views. The liberalism of the later Rawls is not based on an ideal of autonomy, but on the notion of free and equal citizens, an ideal that can be shared, he claims, regardless of one's views on morality. Kantians and utilitarians can both agree on the importance of equal citizenship, and this ideal is, then, where the justification of Rawls's principles of justice start. It seems to me that, with a little work, Kantians, utilitarians, pluralists, resourcists, and proponents of flourishing could all come to agree that BLLS's list of educational goods is appropriate and useful for thinking about what is of value in education.

To take the approach of an overlapping consensus would be preferable to starting from the value of flourishing for the purpose of the BLLS framework. First, such a view would change nothing for those who believe that flourishing is the basis for education since an overlapping consensus would entail the same educational goods. Second, it allows us to get around the problem of neutrality. Third, since it seems that educational goods could make up a shared view for all reasonable positions, or at least, for resourcism, pluralism and the flourishing view, this would make the framework attractive from further moral starting points than only flourishing. Fourth, this solution seems to handle Brighouse and Swift's two reasons for caution about perfectionism at least as well, and probably better, than the flourishing view. Fifth, it does seem like an advantage not to have to solve what may be the central issue of philosophical ethics, what things have fundamental value, before deciding on using the framework or not in educational policy making.

However, one might think that this discussion about flourishing is misplaced since even if it would be inappropriate for the state to decide on which life styles are appropriate for adults, children need guidance, as they have yet to achieve the autonomy of adulthood. On this view, flourishing would be the obviously correct value for children. Indeed, Brighouse says the following in other work: "neutrality is an inappropriate constraint on the state regarding policies concerning children." (Brighouse 2000, p. 103) This seems true, but this argument cannot be used to support the position that educational goods need not be neutral since the educational goods of the BLLS framework are designed to create capacities in adults, and not only children. Moreover, rather than rescuing flourishing, this kind of counterargument indicates a further problem with BLLS's approach, albeit a problem that it shares with most theories on the metric of justice, namely that it is designed with autonomous adults in mind rather than children. How is this a problem for BLLS? It has 
to do with the focus on opportunities for flourishing, rather than flourishing in itself, and fundamentally with the value of responsibility.

Education is provided to children. Children are human beings that for developmental reasons have not yet achieved autonomy. Autonomy is both a capacity and a condition for being held responsible. Opportunity goods are suitable for agents who have autonomy and who are, hence, responsible for their actions. However, opportunity goods are not appropriate for agents who lack autonomy and that are not yet responsible for theory choices. (Cf. Lindblom 2016) What is good for the latter kind of agents is to have goods directly. Opportunity goods are developed on the basis of an ideal of adulthood that does not take the characteristics of children into account. Since children lack the characteristics that make opportunity for flourishing an appropriate distribuendum, it seems clear that from a general flourishing standpoint, the distribuendum for children should be flourishing and not opportunities for flourishing.

Of course, children have an interest in preparation for adulthood, and in this sense, the opportunity for flourishing at a later stage will matter to them, but for them qua children flourishing, rather than opportunity for flourishing, seems the appropriate equalisandum. This is point can also be made more directly from the starting point of childhood and education. Education is not only good because it prepares one for adulthood, but it is also good for one as a child. For instance, it is evidently good for a child to have opportunities for equal standing and good relationships, when he or she becomes adult. But it is also good for a child to be in good relationship and experience equal standing during childhood. This suggests that the theory of distribuendum must be made more complex. Perhaps one should think of it in terms of flourishing for children and opportunities for flourishing for adults; this would take care of the problem of responsibility and opportunity. Or, one could have a distribuendum of resources for adults and flourishing for children, which would seem to handle both responsibility and neutrality but may have other problems. These are quite new and very difficult questions, and it would be unreasonable to demand that BLLS have a final answer to something that is an open question in the literature and debate on childhood (Cf. Lindblom forthcoming). However, I raise this here because it illustrates an issue regarding childhood goods and educational goods, which shows how the BLLS framework may have an implicit bias in favor of adulthood interests over childhood interests.

Childhood goods are goods that are only accessible during childhood or, if also accessible during adulthood, goods that are especially important for childhood flourishing (Cf. Gheaus 2015). The way in which the BLLS framework may be unduly tilted in favor of adulthood over childhood can be illustrated by asking why the independent value of childhood goods would be best thought of as independent from the educational goods. More specifically, if personal fulfillment is an educational good, then why wouldn't this good include childhood goods? We will return to the question of independent values below, but since childhood goods might have a significant connection to educational goods, we will investigate that issue here. A person flourishes when her or his life goes well. Part of a person's life going well is that her childhood goes well. For childhood to go well it has to include goods such as "[p]urposeless play, naïve curiosity, unreserved joy and carefreeness" (Brighouse et al. 2018, p. 37). These goods are examples of what BLLS call childhood goods. This line of reasoning, however, seems to imply that childhood goods should be conceived as a part of educational goods, either as a distinct kind or as a part of personal fulfillment since these goods seem clearly a part of a flourishing. In particular, the distinction between the educational good of personal fulfillment and the independent value of childhood goods seems unjustified, unless one takes the position that education is solely a preparation for adulthood. However, BLLS are very clear about the importance of 
childhood, and say that "childhood is itself part of a life, and the flourishing enjoyed during it should not be discounted." (2018, p. 20) Yet, the view that education is for preparation for adulthood seems to be an implication of their framework. It also seems like a common sense view; we educate children for the sake of their future. Nonetheless, I claim that it is neither an obviously justified view nor a part of the common sense position that education is solely for preparation for adulthood, but rather that we tend to, and have reason to think that education is primarily for preparation.

Here is an intuition pump: Assume that technological developments advanced to the stage where it would be possible to download knowledge, skills, dispositions, and attitudes directly into the brain. Would something, then, be lost if we opted to refrain from giving education to children, but instead downloaded the full set of knowledge, skill, dispositions, and attitudes on the morning of their first day of adulthood? It seems to me that the answer is to this question is yes, something of value would be lost. In particular, the childhood good of experiencing curiosity and having it satisfied, which schooling provides, would be lost. This indicates that at least some childhood goods are educational goods. Moreover, children would in this scenario be deprived of the direct effects of educational goods, such as personal fulfillment. The experience of reading and understanding a challenging novel or being able to explain a natural phenomenon is valuable to a child directly, and not only for the preparation it provides for adulthood. Being in healthy relationships, experiencing equality in standing, exercising some forms of democracy and even being able to be economically productive are also of direct value to children. In all these ways, something would be lost by abolishing education even it was unnecessary for preparation for adulthood. Of course, if downloading the content of education would become possible, which it probably never will, this would change how education was provided. We would probably spend fewer resources on education, but we would not stop providing it altogether. This shows, I claim, that while we do think of education in terms of preparation, we do not think of it solely in those terms. Moreover, this shows that holding educational goods and childhood goods distinct in the manner suggested by BLLS would risk mischaracterizing the decision problem that educational policy makers face.

Here is another way of getting to the conclusion that childhood goods should be included in some form in the list of educational goods. It is a version of a thought experiment devised by Macleod (2010). Compare two schools. One has an abundant program for extra-curricular activities, where the children play and perform. The other school does not have any such program. The first school provides for childhood goods to a great extent and the second school does so to a very low degree. However, both are equally successful in providing the pupils with a preparation for adulthood. Now, assume that you are a parent with the sole goal of choosing the best possible education for your child and that these two schools are your only two options. If all there is to education were preparation, this would be a Buridan's Ass kind of choice, but since it is not that kind of choice, it follows that education is not only about preparation. The first school is a better school and it provides a better education. This in turn implies that childhood goods are educational goods. There is also a second reason, which is more in line with Macleod's original intentions with the thought experiment, to think that childhood goods are educational goods. The inequality between the schools seems unfair to the students in the second school. However, if preparation is all that matters it cannot be formulated as an educational inequality. If we think of childhood goods as educational goods, we get this intuitive result which appears to be a further reason to include childhood goods in the category of educational goods.

This has been a long and winding discussion, so let us sum up. In this section, we have been occupied with the derivation and individuation of educational goods in the BLLS 
framework. I have claimed, first, that the framework could and should be based on a less controversial foundation than flourishing and have suggested that the ideal of an overlapping consensus would provide such a starting point for the grounding of educational values. Secondly, I have agreed with BLLS about the importance of taking childhood into account when designing a framework for the area of education, but disagreed with them about how this is best done. Here, I have advanced two claims. The first of these is that the problem of the distribuendum for children is complex, but even if all problems regarding that issue cannot be expected to be resolved within the framework, we should think of children as being owed goods directly, even if opportunity goods are appropriate for adults. The second claim is that childhood goods should be thought of as educational goods since not only adulthood but also childhood is an important stage of life in itself, and therefore educational goods cannot only be preparatory goods.

\section{Distributive Principles}

BLLS make the important point that it is not enough for policy purposes to list the goods at stake, one also needs to show what principles should guide the pursuit of these goods. They take on this task by listing three distributive principles that play a role in educational policy. These are, first, adequacy, which is that view that the distribution of a good should be such that each person has an adequate amount of it, where adequate is interpreted in terms of some goal such as earning a living wage or being a citizen on equal standing with others. Secondly, there is equality, which, straightforwardly, implies that goods should be distributed so that each person has an equal share. The third principle is that of benefitting the least advantaged, which "demand distributions that serve, over time, to benefit the less advantaged." (Brighouse et al. 2018, p. 34) BLLS do not take a stand on which of these is the correct principle, or what is the relative weight of these principles when they have to be traded off against each other. This is left, reasonably, to the decision maker using the framework. However, they are a little less than fully explicit concerning exactly what this trade-off is a trade-off between since these are not the only distributive principles in the framework. BLLS initially presented the framework as "a consequentialist framework for educational decision making." (Brighouse et al. 2016, p. 5) In Educational Goods they say that "[a] decision maker will need to consider not only the total amount of educational goods but also how those goods are distributed across individuals" (Brighouse et al. 2018, p. 2). This seems to imply that the distributive principles will have to be weighed against considerations of efficiency. Since efficiency is probably as controversial as, e.g., equality, as principle for distributing educational goods, it would have been useful with a little more discussion of this principle.

BLLS note that "[d]istributive values typically have two components: (1) a distributive principle and (2) an object of distribution to which the principle applies." (Brighouse et al. 2018, p. 31) In their framework, educational goods make up the distribuendum, even if, as we have seen, opportunities for flourishing is the fundamental value. The distributive principles are the ones we listed above. However, distributive principles, and theories of distributive justice in general, tend to have at least two further components, and depending on how those are spelled out, the principles imply different policy prescriptions. These components are the domain of distribution and the timeframe of distribution. The purpose, then, of this chapter is to suggest that BLLS framework can and should be complemented with these two further components. 
The simplest way of illustrating what is at stake with regards to the domain of distribution is to point to the debate of global justice. Very roughly there are two positions, either the domain of distributive justice is the whole world, or the domain of this value is individual countries and other kinds of principles, such as a principle of humanity, should regulate the relationships between different countries (Cf. Rawls 1999). The debate on global justice is, in this sense, a debate over the domain of the principles of distributive justice. The issue of the domain gained prominence through Walzer's (1983) theory of the spheres of justice, in which he claimed that society comprises of a set of spheres-the market, health care, etc.- and that different principles were appropriate for different spheres. The right principle for health care would be to distribute according to need, and in the market sphere desert should be the master principle. Now, I do not claim that educators should take Walzer's or Rawls's theories to heart, but only point out that the BLLS framework raises the issue of the domain of distributive principles and that these should be addressed within the framework.

Here is a simplified example to illustrate the implications of different frames. Assume that you are a policy maker tasked with achieving an equal distribution of educational goods, and you can choose between two options. The first option is that all students read one key novel from the history of literature, whereas the second alternative is that only children from disadvantaged backgrounds read important novels but that they get to read five such novels. Which one of these policies should someone aiming at educational equality prefer? The answer depends on what domain the principle of equality has. On the one hand, if what is important is how the institution of the school distributes educational goods, then the first option is plainly more equal. On the other hand, if what is important is the overall impact of all institutions, including the family and public libraries, on the level educational goods children get, then the second option could be the more equal of the two. This difference in implications does not have to do with either the distribuendum or the kind of distributive principle used.

The difference between the two options is that for the first the focus is on what we may call institutional justice, i.e., justice with regards to the impact of a specific institution, whereas the second option revolves around what may be termed systemic justice, meaning justice with regards to the full set of institutions in a society. This distinction is purposely formulated in very general terms to cover different specific views. The central point is that since we may have both those approaches to justice in mind when thinking about justice, it is imperative to make clear that they are distinct views with different implications for what it means to strive for justice. BLLS's discussion of distributive principles indicates that they conceive of the distributive problem of education as taking place on the systemic level (Brighouse et al. 2018, pp. 31-36), but it would seem preferable to be able to make this distinction within the framework, even if one has the view that only one of the levels are really important. It might be the case that we should never think about institutional educational impacts in isolation but always in terms of systemic justice - this would not be an implausible view - but it would seem useful to at least be able to express the opposite view in a framework designed to support educational decision makers.

Moreover, by making room for the distinction between institutional and systemic justice a further point about the distributive principles in the framework becomes salient, namely that the instrumental relationship between levels is potentially significant for trade-offs in education policy. The actual principles that educators should use in deciding on policy may be others than those that we ought to use in evaluating the outcomes of the policy. It might, for instance, be the case that aiming for efficiency in the educational system with regards to educational goods may be a way to achieve systemic equality of such goods. This could 
be so if other institutions offset the unequal effects that this focus on efficiency has in such a way that the resulting outcome is equal, for instance through on-the-job training and a well-functioning sphere of democratic discourse. Or it could be that the best way to achieve sufficiency on the systemic level would be a focus on equality on the institutional level of education. The point here is not that any of these instrumental relationships actually hold, but that choosing with the help of a specific principle is not necessarily the best way of achieving the goals of this principle, especially within a system of institutions that all may affect the outcome.

What are the implications of this discussion for the BLLS framework? First, it should include a conceptualization of the domain of distributive principles. Second, a distinction between institutional and systemic justice makes sense of some of our intuitions and is arguably a useful candidate for inclusion in the framework, but perhaps other ways of expressing the issues at stake may be even more appropriate. Third, the distinction between institutional and systemic levels illustrates an important instrumental relationship between levels of justice, and fourth, with that perspective in mind the principle of efficiency becomes saliently important and should be explicitly included as a distributive principle in the framework. A further reason for being explicit about efficiency it that doing so would clarify further that it is one of the contenders for being the appropriate distributive principle and not just something that is a given for educational policy.

We turn now to the timeframe of distribution. BLLS note that one way of benefitting the least advantaged would be to allow or create inequalities of educational goods. If it is the case that the better off become more productive when being additionally rewarded, and the result of this productivity could be turned into more educational goods to be redistributed to the least advantaged, then the resulting inequality would make the least advantaged better off than they would have been if there were no such inequalities. A case where this principle could apply is where Peter due to his abilities is granted extra goods to the detriment of the less able Paul. The answer to Paul (or his parents) when he asks why fewer resources are spent on him than on Peter, is that it is better for Paul to have this inequality than to have an equal distribution of educational goods. However, it is not clear that this answer can always be plausibly formulated in the terms of the BLLS framework. If the goods at stake are educational goods and such goods are, for developmental reasons, especially important to have access to in youth, and also only or primarily allocated to children and adolescents rather than adults, then it is not clear that Paul is compensated for the inequality at all. He will be an adult at the same time as Peter, and the gains in Peter's productivity will not lead to any further educational goods for Paul. Given the circumstances of education, in terms of time, inequalities might not benefit the least advantaged in such cases.

At this stage, it is useful to spell out some different approaches to the timeframe. One approach is to think of distributive principles as applying instantaneously at all times. For example, what equality demands would then be that the distribution of goods should be equal at each time. The principle of benefitting the least advantaged could be seen as opposed to this view of the timeframe. A principle that said that one should benefit the least advantaged maximally at each time would imply that the distribution of goods should be equal at each time, which would make the two distributive principles indistinguishable. This suggests a second approach to timeframes, namely, that what is of importance is the distribution of goods over a lifetime. With this timeframe, it seems easier to make sense of the case of Peter and Paul. Over a whole life, Paul will be able to enjoy a higher level of goods (even if they are not educational goods) than he would have been able under an equal distribution of goods. However, some problems remain that might necessitate a further timeframe. 
Some goods are especially important at specific times. For instance, there are at least three reasons for providing education in childhood, rather than, say, in old age. First, and obviously, one needs to be educated when entering adulthood. However, a second reason, as BLLS note, is that due to the way in which human beings develop, education is much more effective in childhood and adolescence than at later times in life (Brighouse et al. 2018 , p. 19). Thirdly, some aspects of educational goods may turn out to fall under the heading of intrinsic goods of childhood, and as such could not be fully compensated for later in life (Cf. Brennan 2014). A higher salary might not compensate for a childhood without play. The two latter reasons indicate that there is a need for a timeframe in between whole lives and instances. Let us call this the developmental stage timeframe.

To illustrate, it might be the case that one would have to apply the principle with up to three timeframes in the case of Peter and Paul. When we think about choices regarding the good of economic productivity, then it seems that losses to Paul during childhood could be compensated by better prospects in adulthood. But, if our choices have to do with personal fulfillment regarding goods that only or mostly accessible in childhood, a timeframe which takes developmental stages into account seems more appropriate. In such cases, the loss of childhood goods for the least advantaged can be compensated for at a later stage of childhood, but due to the kind of goods at stake, not during adulthood. Finally, it might seem that the instantaneous timeframe has little use, but there might be cases when it is the most appropriate of the alternatives. Take the case of the educational good of regarding each other as equals. It is not clear that a step away from students regarding each other as equal is ever justified.

Summing up, the argument is not at that educational decision makers should think about the case of Peter and Paul in some specific way, e.g., the way I have done above, but that the framework should be designed so that thinking this way makes sense in the terms it provides. The argument is not that we should think of policy choice in terms of any specific timeframe, be it instantaneous, developmental phases or whole lives, or that we should weigh timeframes in any particular manner. The point is that in making use of distributive principles, timeframes matter and should have a place in the framework for educational decision making.

\section{Independent Values}

The third and final category of values in the BLLS framework is independent values. These are values that are not educational goods or distributive principles, but still are relevant for education. The list of such values are potentially endless, but BLLS identify the following as especially relevant: "childhood goods, parents' interests, respect for democratic processes, freedom of residence and of occupation, and other goods" (Brighouse et al. 2018, p. 37). We discussed childhood goods above, but the other values need some explanation. Under the heading of parents' interests BLLS note that it is beneficial for children to have parents who have authority over them, and that parents' justified use of this authority can come into conflict with both the pursuit of educational goods and distributive principles (Cf. Brighouse and Swift 2014). By respect for the democratic process BLLS mean that democratically chosen policies rightfully constrain what can be done to pursue educational goods. Sometimes one has to settle for worse educational outcomes for democratic reasons. Freedom of residence and occupation covers cases where citizens' liberties constrain the pursuit of educational goods. Drafting teachers to specific schools or restricting the 
freedom of choosing where to live may be ways of producing more or more equally distributed educational goods, but doing so would conflict with essential liberties. Other goods is a category that is needed to make the point that "[d]ecisions about how much to spend on education affect what is available for investment in other government and private activities - health, transportation, housing, environmental protection, and so on." (Brighouse et al. 2018, p. 41)

Independent values are identified by BLLS by their propensity to come into conflict with the pursuit of educational goods: "Educational goods make an important contribution to flourishing, but so do many other goods that compete with them for resources." (Brighouse et al. 2018, p. 36) Parental interests' may be at cross purposes with giving the best possible education to their children. For instance, any amount of money spent on education could always have been spent on health, housing or transportation instead. All these independent values compete with educational goods and function as constraints on the pursuit of them. I shall argue that this focus on constraint mischaracterizes the decision problem that the educational decision maker faces in two respects. First, to take independent values into account when making such decisions should mean both taking values that constrain and values that support education into account. Supporting independent values should also have a place in the framework. They also make key contributions to flourishing (or resources etc.). Second, the list of constraining independent values included in the framework, in fact contains values that should be interpreted as both constraining and supporting the pursuit of educational goods. The BLLS framework is intended to aid policy makers in making trade-offs with regards to the pursuit of educational goods, but if the description of the decision problem focuses only on those things that compete with educational goods, then less educational goods risk being produced than would be optimal. If also supportive independent goods are included in the description of the decision problem, it seems more likely that the policy makers will reach the optimum decision.

With regards to the first point above, then, there seems to be no reason for why there could not be values that are independent of education and yet supportive of education. One example could be esthetic values. One could think that beauty is important regardless of its impact on personal fulfillment, which seems to be the educational goods most closely positioned to this value. For example, one could find it important that the works of Michelangelo continue existing even if would happen that no one liked them anymore. Or, one could be of the view that the beauty of untouched nature is important for its own sake and not only for its impact on human well-being. If there is a causal relationship between education and the preference to create or maintain beauty, so that beauty is served by education but not an educational good, then this would be an example of a supportive independent value. If one wants to promote beauty, then one has reason to support education since doing so will instrumentally promote beauty. Moreover, knowledge in itself, rather than as an aspect of educational goods, is not an educational good in the BLLS framework, and neither is it an independent value, but surely the plain value of understanding the world could be an independent value relevant to educational decision making. This would amount to another supportive independent value. Of course, BLLS are working under the constraint of creating a feasible framework for actual decision making, and cannot be expected to include every possible value in their model. Not doing so seems to me to be fully justifiable. However, the conclusion here must at least be that the discussion of what independent values ought to be included in the framework should continue and that the onus of proof seems to be on those who do not include supportive independent values.

When it comes to the second point made above, it seems more straightforward that some revision of the framework is in order. The aspects of the independent values which 
constrain the pursuit of educational goods are brought to the forefront, whereas potential aspects that support educational goods get little to no mention. One example of this is the relationship between the content of independent values and the political sphere. For plausible reasons of framework construction, BLLS leaves the exact contours of freedom of residence vague, but it is clear that they assume that this liberty can constrain policy designed to limit segregation and that it supports a free market in housing. Such policies would be less far-reaching constraints on freedom than the drafting of teachers, but at least some aspects of residential zoning and state interventions in the housing market are ruled out. If this is so, then residential zoning, as an independent value, restricts the pursuit of educational goods, but it cannot be used to support educational goods. The fundamental reason for this, in the BLLS framework, is that this approach promotes opportunity for flourishing. However, the duty to pay taxes, on properties or otherwise, also promotes opportunity for flourishing, but it is not a part of the list of independent values. This seems problematic. Especially for educational systems that fund education through property taxes, one approach to the constraints given by the freedom of residence would be to leave the zoning as it is but change the way that property is taxed to improve educational outcomes. BLLS note as much when they say that one could "consider other measures that impose costs on residential choice, like imposing higher tax rates on properties in wealthy residential areas than on properties in socio-economically mixed neighborhoods." (Brighouse et al. 2016, $\mathrm{p}$ 18) Both taxes and residential zoning are straightforwardly political questions with high relevance for the educational system, and both consistency and the realism of the framework would imply that both should be included explicitly as independent values.

The difference between freedom of residence and taxation is that one is a liberty and the other implies a duty. The value complexes that independent values refer to contain both constraints and possible support, or to put it another way, they contain both liberties and duties. Childhood goods are interpreted by BLLS as constraints on educational goods, but I have argued that they are educational goods in themselves and so that supporting them means supporting an educational good. Parents' interests are framed in terms of the rights of parents, but parents have both rights and duties. Respect for the democratic process means both abiding by democratically decided laws and refusing to follow nondemocratic rules. The freedoms of residence and choice of occupation are part of the civil rights and duties of citizens, but there is also the duty to pay one's fair share of taxes. Finally, among other goods, there is the good of consumption, but there may well also be goods like esthetic values, nature, art and even knowledge itself. Independent values should be formulated so that both liberties and duties are explicit and so that both constraining and supporting aspects of values are visible in the framework.

This, however, does not mean that educational decision makers will have it within their power to affect policy with regards to all aspects of these values. This brings us to a further way that constraints come into play in the BLLS framework. This is most directly described in their (2016) article where they say that they.

assume that the decision makers in question have limited ability to affect the context within which the schooling system is nested... [and] that some aspects of society are outside of the decision makers control. Even with these constraints, decision makers have some discretion over educational decisions and the framework that we outline can help to guide them. (Brighouse et al. 2016, p. 5)

This constraint on the pursuit of educational goods is, it seems, distinct from the one inherent in the independent good of respect for the democratic process. Otherwise, it would seem unnecessary to state it as its own standalone point. But if this is a distinct constraint, it is not 
motivated by any of the independent goods that BLLS list. There are, in this way, two levels of political constraints involved in BLLS's approach, both practical constraints and respect for the democratic process. Respect for the democratic processes implies being constrained by other democratically justified part of the political system. The pure unfeasibility, however, of pursuing presumed educational values in some practical circumstances does not imply that those goods should not be sought after, especially in other circumstances where they can plausibly and practically be promoted. This, then, seems to amount to one level of constraint too many in the BLLS framework, given that the important normative work is already done by the good of respect for the democratic process.

Another way of getting at this point is to think about the conception of education at work in defining what is a value relevant for education and what is an independent value. There are many ways to define education but one would be hard-pressed to find a wider conception than that in John Stuart Mill's A System of Logic, where he defines the science of ethology as corresponding with the art of education "in the widest sense of the term, including the formation of national character as well as individual." (Mill 2012 [1843], pp. 522-523) Now, a rather obvious counterargument against thinking about education in this wide sense would be that the systems of education cannot plausibly be tasked with such a massive undertaking. How could teachers be expected to practice an art of education that forms national and personal character given that so much else also affects character development? A conception of education appropriate for making choices in the actual systems of education that exist must be much narrower, it seems. However, while it is true that neither teachers nor educational administrators have it within their power to fully implement goals like those of Mill's account of education, it does not follow that they should not take those aspects outside of their power into account. Nor does it follow that our conception of education should do so. To return to the terminology introduced in a former chapter, the institution of education, as a part of the social system, should be designed to support the full implementation of the principles of systemic justice. It would be a mistake to narrow down the conception of education, because one institution is unable to implement, by itself, a system-wide principle of educational justice. What does this mean for the BLLS framework? It means that the independent values of the framework should include those values that are relevant for education in the wide sense, even if it is not within the power of teachers and administrators to control policy regarding those values. If not all values are included, then the policy problems of the educational system are mischaracterized.

To sum up, the problem with the way that the BLLS framework distinguishes between educational goods and independent values is that it only identifies values that constrain the pursuit of educational goods. I have argued that three things should be done. First, the framework should take into account independent values that support education, and not only such values that constrain it. Second, the independent values that are included in the framework should be re-interpreted in such a way that both aspects that constrain and that support the pursuit of educational goods become salient. Finally, there is one level of constraint too many in the framework, and this may mispresent the decision problem that the policy maker faces.

\section{Concluding Remarks}

The purpose of the BLLS framework is to provide a language for educational decision makers and researchers to discuss values and trade-offs in education. As my discussion of the framework has shown, this is something they have succeeded with admirably. Moreover, the analyses of different areas of educations policy in the second half of Educational 
Goods clearly illustrate the usefulness of their approach. Furthermore, the general approach of distinguishing between educational goods, distributive principles and independent values makes much sense of the normative problem that educational decision makers face. The BLLS framework is, to my mind, a success. However, it seems to me that there is still room for some improvements. I have identified three such areas where further work seems necessary. I have claimed, firstly, that the normative foundation for the educational goods should be an overlapping consensus rather than an account of flourishing, and I have also argued that childhood goods belong in the category of educational goods. Secondly, the BLLS account of distributive principles should include something along the lines of the distinction between institutional and systemic justice and be amended with an account of the timeframe of distribution. Finally, I have argued that independent values should be framed in a way that makes both liberties and duties explicit and includes both aspects that constrain and such that support the pursuit of educational goods.

Acknowledgements I would like to thank Kalle Grill, as always, for helpful comments.

Funding This study was funded The Swedish Research Council (Grant Number 2013-2337).

\section{Compliance with Ethical Standards}

Conflict of interest The author declares that he has no conflict of interest.

Open Access This article is distributed under the terms of the Creative Commons Attribution 4.0 International License (http://creativecommons.org/licenses/by/4.0/), which permits unrestricted use, distribution, and reproduction in any medium, provided you give appropriate credit to the original author(s) and the source, provide a link to the Creative Commons license, and indicate if changes were made.

\section{References}

Berlin, Isaiah. 2013. The Crooked Timber of Humanity: Chapters in the History of Ideas. 2nd ed. Princeton: Princeton University Press.

Brennan, Samantha. 2014. The Goods of Childhood, Children's Rights, and the Role of Parents as Advocates and Interpreters. In Family-Making: Contemporary Ethical Challenges, ed. Françoise Baylis and Carolyn McLeod, 29-48. Oxford: Oxford University Press.

Brighouse, Harry. 2006. On Education. London: Routledge.

Brighouse, Harry. 2000. School Choice and Social Justice. Oxford: Oxford University Press.

Brighouse, Harry, and Adam Swift. 2014. Family Values: The Ethics of Parent-Child Relationships. Princeton: Princeton University Press.

Brighouse, Harry, and Adam Swift. 2018. Family Values Reconsidered: A Response. Critical Review of International Social and Political Philosophy 21: 385-405.

Brighouse, Harry, Helen F. Ladd, Susanna Loeb, and Adam Swift. 2016. Educational Goods and Values: A Framework for Decision Makers. Theory and Research in Education 14: 3-25.

Brighouse, Harry, Helen F. Ladd, Susanna Loeb, and Adam Swift. 2018. Educational Goods: Values, Evidence, and Decision-Making. Chicago: University of Chicago Press.

Dworkin, Ronald. 2000. Sovereign Virtue. Cambridge: Harvard University Press.

Gheaus, Anca. 2015. 'The Intrinsic Goods of Childhood' and the Just Society. In The Well-Being of Children in Theory and Practice, ed. Alexander Bagattini and Colin MacLeod, 35-52. Dordrecht: Springer.

Lindblom, Lars. 2016. Equality of What for Children. In Justice, Education and the Politics of Childhood, ed. Johannes Drerup, Gunter Graf, Christoph Schickhardt and Gottfried Schweiger, 89-100. Berlin: Springer.

Lindblom, Lars. forthcoming. Children and the Metric of Justice. In The Routledge Handbook of the Philosophy of Childhood and Children, ed. Anca Gheaus, Gideon Calder and Jurgen De Wispelaere. London: Routledge. 
Macleod, Colin. 2010. Primary Goods, Capabilities, and Children. In Measuring Justice: Primary Goods and Capabilities, ed. Ingrid Robeyns and Harry Brighouse, 174-192. Cambridge: Cambridge University Press.

Mill, John Stuart. 2012. [1843] A System of Logic, vol. 2. Cambridge: Cambridge University Press.

Rawls, John. 1971. A Theory of Justice. Oxford: Oxford University Press.

Rawls, John. 1999. The Law of Peoples. Cambridge: Harvard University Press.

Rawls, John. 2001. Justice as Fairness: A Restatement. Cambridge: Harvard University Press.

Walzer, Michael. 1983. Spheres of Justice: A Defense of Pluralism and Equality. New York: Basic Books. 